\title{
Full-Scale Spectrum of Boundary-Layer Winds
}

\author{
Larsén, Xiaoli Guo; Larsen, Søren Ejling; Lundtang Petersen, Erik
}

\section{Published in:}

Boundary-Layer Meteorology

Link to article, DOI:

$10.1007 / \mathrm{s} 10546-016-0129-x$

Publication date:

2016

Document Version

Peer reviewed version

Link back to DTU Orbit

Citation (APA):

Larsén, X. G., Larsen, S. E., \& Lundtang Petersen, E. (2016). Full-Scale Spectrum of Boundary-Layer Winds. Boundary-Layer Meteorology, 159, 349-371. https://doi.org/10.1007/s10546-016-0129-x

\section{General rights}

Copyright and moral rights for the publications made accessible in the public portal are retained by the authors and/or other copyright owners and it is a condition of accessing publications that users recognise and abide by the legal requirements associated with these rights.

- Users may download and print one copy of any publication from the public portal for the purpose of private study or research.

- You may not further distribute the material or use it for any profit-making activity or commercial gain

- You may freely distribute the URL identifying the publication in the public portal

If you believe that this document breaches copyright please contact us providing details, and we will remove access to the work immediately and investigate your claim 


\section{Full scale spectrum of boundary-layer winds}

2 Xiaoli G. Larsén, Søren E. Larsen,

3 Erik L. Petersen

- Abstract Extensive mean meteorological data and high frequency sonic anemome-

7 ter data from two sites in Denmark, one coastal onshore and one offshore, have

$s$ been used to study the full-scale spectrum of boundary-layer winds, over frequen-

9 cies $f$ from about $1 \mathrm{yr}^{-1}$ to $10 \mathrm{~Hz}$. 10-min cup anemometer data are used to

10 estimate the spectrum from about $1 \mathrm{yr}^{-1}$ to $0.05 \mathrm{~min}^{-1}$; in addition, using 20 -

$11 \mathrm{~Hz}$ sonic anemometer data, an ensemble of 1-day spectra covering the range 1

12 day $^{-1}$ to $10 \mathrm{~Hz}$ has been calculated. The overlapping region in these two mea-

13 sured spectra is in good agreement. Classical topics regarding the various spectral

14 ranges, including the spectral gap, are revisited. Following the seasonal peak at

$151 \mathrm{yr}^{-1}$, the frequency spectrum $f S(f)$ increases with $f^{+1}$ and gradually reaches

16 a peak at about 0.2 day $^{-1}$. From this peak to about $1 \mathrm{~h}^{-1}$, the spectrum $f S(f)$

17 decreases with frequency with a -2 slope, followed by a $-2 / 3$ slope, which can be

18 described by $f S(f)=a_{1} f^{-2 / 3}+a_{2} f^{-2}$, ending in the frequency range for which exists and can be modelled. The linear composition of the horizontal wind variation from the mesoscale and microscale gives the observed spectrum in the gap range, leading to a suggestion that mesoscale and microscale processes are uncor- 
deep or shallow, visible or invisible. Generally, the depth of the gap decreases with height. In the low frequency region of the gap, the mesoscale spectrum shows a two-dimensional isotropic nature; in the high frequency region, the classical threedimensional boundary-layer turbulence is evident. We also provide the cospectrum of the horizontal and vertical components, and the power spectra of the three velocity components over a wide range from 1 day $^{-1}$ to $10 \mathrm{~Hz}$, which is useful in determining the necessary sample duration when measuring turbulence statistics in the boundary layer.

Keywords Atmospheric turbulence, Mesoscale velocity spectra, Microscale velocity spectra, Planetary boundary layer, Spectral gap

\section{Introduction}

Spectral analysis is a classical theme. It is central to the study of a number of issues in atmospheric boundary-layer dynamics, among them equations of motions, probability functions of first-order and higher-order moments, structure functions and exceedance statistics. Analysis of wind variation in the frequency or wavenumber domain provides important information for various applications, such as dynamic wind loading and turbulence diffusion of constituents, where turbulent energy in specific frequency bands is directly relevant.

The velocity spectrum has been studied and applied in the context of wind engineering for more than half a century. There remain a series of outstanding questions, including:

- Is there a gap between microscale and mesoscale, centered around $1 \mathrm{hr}^{-1}$ ?

- How do microscale and mesoscale motions interact? Can these motions be considered correlated, uncorrelated, or just weakly correlated?

- In the mesoscale range, how do the spectra vary with height, how do the spectra and cross-spectra of the three wind components (the longitudinal, the transverse and the vertical) vary with height and stability?

In Lumley and Panofsky (1964), the Van der Hoven wind spectrum close to the ground (Van der Hoven 1957) was shown as evidence of the existence of a "gap" at a period of about $1 \mathrm{hr}$, separating the three-dimensional (3D) turbulence from the 


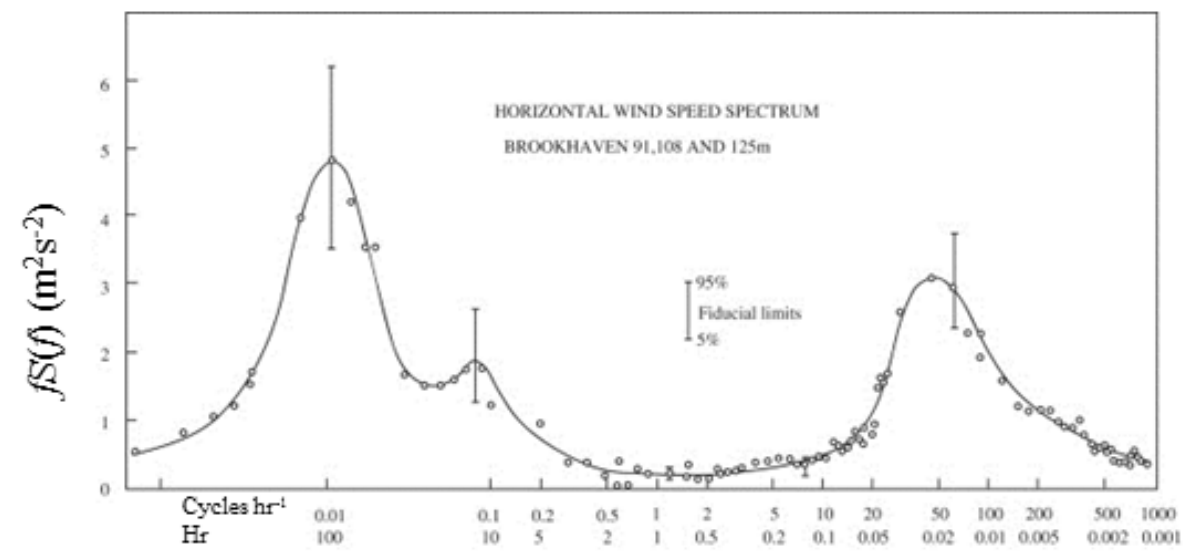

Fig. 1 Horizontal wind-speed spectrum at Brookhaven National Laboratory at about 100-m height, $f S(f)$ against $f$. Reproduced from Van der Hoven (1957).

two-dimensional (2D), mesoscale to macroscale motions. The authors stated: "It can be seen that such a gap exists, which makes the prospect of applying our ideas in meteorology seem attractive". Kaimal and Finnigan (1994) stated:"Implicitly in the development of spectral forms in the energy-containing range is the assumption that a spectral gap exists, separating boundary-layer turbulence from external fluctuations." They also cited the Van der Hoven spectrum as evidence, shown in Fig. 1. When analyzing measured turbulence, the basic assumption on ergodicity and stationarity requires existence of the gap. It is because the assumption of stationarity implies the existence of a correlation integral time scale, which in turn implies that the frequency spectrum $f S(f)$ of e.g. boundary-layer turbulence must be limited at low frequencies by a $f^{+1}$ dependence, according to the WienerKhintchine theorem for a stationary, random process. Here, $f$ is the frequency. In the atmospheric boundary layer, the existence of a $f^{+1}$ spectral range of $30-60$ min lends credibility to considering the fast fluctuations as stationary processes and hence to analyze the time series through statistically stationary theories and models. In terms of processes, the spectral gap therefore constitutes the lower frequency limit for boundary-layer turbulence, being responsible for the fluxes between the surface and the atmosphere. 
The search for the gap historically goes back to the early fifties (Panofsky and McCormick 1954; Panofsky and Van der Hoven 1955; Griffith et al. 1956). Over the years there have been numerous discussions on wind velocity spectra, the shape of the spectrum, and the division into microscale and mesoscale due to the gap (Fiedler 1971; Fiedler and Panofsky 1970; Goldman 1968; Oort and Taylor 1969; Vinnichenko and Dutton 1969; Vinnichenko 1970; Smedman-Högström and Högström 1974; Vickers and Mahrt 2002; Weinstock 1980; Atkinson 1981; Heggem et al. 1998; Courtney and Troen 1990; Troen and Petersen 1989). Most studies describe a near-surface gap observed at periods of the order of $1 \mathrm{hr}$. Sometimes the gap was not observed and some studies interpreted this as due to features such as longitudinal vortices, rolls, jets and convective cells. (LeMone 1976; Smedman 1991; Smedman et al. 1995; Heggem et al. 1998).

It has been questioned by many whether the study by Van der Hoven really proves that the gap exists, e.g. Goldman (1968). His spectrum was patched together from spectral analysis of eight time series covering periods from 1 yr to 1 hr. What really has set a question mark over the proof of a gap comes from the fact that the high frequency region was measured during the passage of a hurricane. This issue reflects one of the major challenges in finding the gap: lack of time series long enough to cover the range from high frequency turbulence and the transition into the mesoscale. Courtney and Troen (1990) and Troen and Petersen (1989), in the Lammefjord experiment (LAMEX), overcame this difficulty by applying the latest optical disk storage devices. A 1-yr record of $8-\mathrm{Hz}$ data was analyzed and they found that a spectral gap can be identified but is not as deep as expected.

Högström et al. (2002) divided a measured horizontal velocity spectrum from $4 \times 10^{-5} \mathrm{~Hz}$ to $10 \mathrm{~Hz}$ into four ranges; their Fig. 4 shows the mean longitudinal velocity spectrum normalized with the friction velocity $u_{*}, f S(f) / u_{*}^{2}$, plotted against frequency, $f$ in $\mathrm{Hz}$. We indicate their four ranges on top of our Fig. 3d. Range $i$ is the Kolmogoroff inertial subrange, where the spectrum is characterized by a $-2 / 3$ slope; range $i i$ corresponds to the so-called shear production range (Tchen et al. 1985), where the spectrum is characterized by a plateau $f S(f) / u_{*}^{2} \approx \gamma$ with $\gamma \approx 1$; range iii corresponds to a spectrum characterized by $f S(f) / u_{*}^{2} \propto f$ and in range $i v f S(f) / u_{*}^{2}$ increases with decreasing $f$. Ranges $i$ to $i i i$ represent boundary-layer turbulence, while ranges $i i i$ and $i v$ are separated by a spectral gap. 
In comparison to boundary-layer turbulence, the spectrum at frequencies lower than the spectral gap has been relatively less studied and understood. Measurements and theory have suggested the following spectral behaviour for scales between several hundreds of $\mathrm{km}$ to a few $\mathrm{km}$,

$$
E(k)=d_{1} k^{-5 / 3}+d_{2} k^{-3}
$$

where $k$ is the wavenumber in $\mathrm{m}^{-1}, E$ is the power spectrum in the $k$ domain, with coefficients $d_{1} \approx 9.1 \times 10^{-4} \mathrm{~m}^{4 / 3} \mathrm{~s}^{-2}$ and $d_{2} \approx 3.0 \times 10^{-10} \mathrm{~s}^{-2}$, e.g. Gage and Nastrom (1986) and Lindborg (1999). Similar spectral behaviour was observed from climatological, long term time series in the frequency domain in Larsén et al. (2013) for scales from several days to about $10 \mathrm{~min}$,

$$
S(f)=a_{1} f^{-5 / 3}+a_{2} f^{-3}
$$

where $a_{1}=3 \times 10^{-4} \mathrm{~m}^{2} \mathrm{~s}^{-8 / 3}$ and $a_{2}=3 \times 10^{-11} \mathrm{~m}^{2} \mathrm{~s}^{-4}$. The range $i v$ as in Högström et al. (2002) is seemingly located in the region where the spectral slope is $-5 / 3$ as in Eqs 1 and 2. The -3 slope part of the spectrum corresponds to geostrophic turbulence, interpreted generally to be related to the baroclinic instability.

For improved clarity, we address the various frequency ranges as follows: in macroscale: $1 \mathrm{yr}^{-1} \lesssim f \lesssim 1$ day $^{-1}$, with the high frequency bound where the spectral slope, $S(f)$ versus $f$ in the $\log$-log scale, of -3 meets the spectral slope $-5 / 3$; in mesoscale: $1 \mathrm{day}^{-1} \lesssim f \lesssim 1 \mathrm{hr}^{-1}$, where the spectral slope is $-5 / 3$; in microscale: scales smaller than the gap range where the spectrum corresponds to 3D boundary-layer turbulence.

The purpose of our study is to improve our knowledge of the full scale velocity spectrum from the order of $1 \mathrm{yr}^{-1}$ to the microscale inertial subrange, by using a consistent calculation approach to extensive datasets of both 10-min mean wind data and sonic turbulence measurements.

The measurements are introduced in Sect. 2, and the method by which the spectra are calculated, analyzed and presented is given in Sect. 3. Results are presented in Sect. 4, followed by discussions and conclusions in Sects. 5 and 6 . 


\section{Observations}

The long term observations were obtained from two sites in Denmark, Høvsøre and Horns Rev (Fig. 2). Høvsøre is a coastal site on land, less than $2 \mathrm{~km}$ from the coast and Horns Rev is offshore, with the shortest distance about $20 \mathrm{~km}$ from the shore.

For Høvsøre, we analyzed both 10-min time series and sonic anemometer data from the years 2012 and 2013. Coverage of the 10-min averaged wind data is $98.4 \%$ for 2012 and $97.9 \%$ for 2013 . The 10-min averaged winds are available at heights $10 \mathrm{~m}, 40 \mathrm{~m}, 60 \mathrm{~m}, 80 \mathrm{~m}, 100 \mathrm{~m}$ and $116.5 \mathrm{~m}$ and all data are used in the analysis. The $20-\mathrm{Hz}$ wind components were obtained at heights $10 \mathrm{~m}, 20 \mathrm{~m}, 40 \mathrm{~m}, 60 \mathrm{~m}$, $80 \mathrm{~m}$ and $100 \mathrm{~m}$. Here, we use turbulence measurements from heights $10 \mathrm{~m}, 20 \mathrm{~m}$, $80 \mathrm{~m}$ and $100 \mathrm{~m}$ because data quality and data coverage at $40 \mathrm{~m}$ and $60 \mathrm{~m}$ are problematic. Standard meteorological and turbulence measurements were made at the same mast, which is $116.5 \mathrm{~m}$ tall. Horizontal wind profiles were measured with cup anemometers and wind vanes, and the $3 \mathrm{D}$ turbulence properties were measured with sonic anemometers. Details of the instrumentation, including influences on the measurements from the mast and the row of wind turbines, can be found in Peña et al. (2015). The mast was at the southern end of a row of turbines in the north-south direction; on average, measurements at the mast suggest that about $2 \%$ of the time, the wind direction is from the sector $0^{\circ}-25^{\circ}$ where wakes may be present. Unfortunately there are no records of turbine operation and generation of wakes that would affect the turbulence signals obtained from the mast. Therefore it is not possible for us to quantify the uncertainty caused by the wakes in the current analysis. In connection with the spectrum calculation using the sonic data, we require that for each day, data coverage $>99.95 \%$, which leads to fewer useful days from each year. Statistics regarding the chosen days and the data availability are presented in Table 1 for each year and at the four levels. Note that the data at $100 \mathrm{~m}$ are less dense than at the other levels. For the spectral analysis for low frequencies, the 10-min mean wind-speed time series from 2005 to 2014 are used.

For the offshore site Horns Rev (Fig. 2), we use both 10-min mean cup data (1999 to 2006) and turbulence measurements (1999 to 2005) from Mast 2 (Larsén et al. 2013). Data are available from 1999 to 2006. The wind farm (www.hornsrev.dk) 


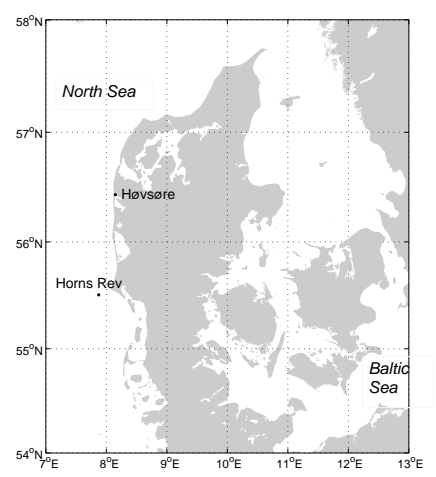

Fig. 2 Map of Denmark and the locations of the two sites Høvsøre and Horns Rev.

was in operation from December 2002. Before this, instruments are not influenced by the wind farm, but since 2003, the data could have been affected by the wakes from the wind farm if the wind direction is from the sector $130^{\circ}-160^{\circ}$. Out of 498 days with turbulence measurements (Table 2), for 19 days the wind direction is from that sector and these days were not included in the calculation. The turbulence was available from sonics at $20 \mathrm{~Hz}$ for years 1999 and 2000, but at $12 \mathrm{~Hz}$ since 2001. Wind speeds were measured with cup anemometers and they are available at $15 \mathrm{~m}, 30 \mathrm{~m}, 45 \mathrm{~m}$ and $62 \mathrm{~m}$ while turbulence measurements were obtained from one single level, $50 \mathrm{~m}$. Yearly data coverage for wind speed varies from $60 \%$ to $99.9 \%$ (Table 1 in Larsén et al. (2013)). Table 2 lists the number of days in each month where turbulence data are available.

\section{Method}

We aim at obtaining a "climatologically representative" spectrum with frequency from the order of $1 \mathrm{yr}^{-1}$ to $10 \mathrm{~Hz}$. The sonic data at Høvsøre have shown questionable quality for frequencies higher than about $3 \mathrm{~Hz}$, likely caused by flow distortion of the mast when winds are from the north (Peña et al. 2015). All calculation has been conducted to the Nyquist frequency of the time series but the presentation sometimes is limited to a few $\mathrm{Hz}$, which is usually in the inertial subrange where spectral properties are well known. 
Table 1 Turbulence data availability (number of days) at Høvsøre for each month in 2012 and 2013 , where for each day the data coverage is greater than $99.95 \%$. Also shown are sonic anemometer sampling frequency and measurement height $h$.

\begin{tabular}{llllllllllllllll}
\hline Year & $\begin{array}{l}\text { Sampling } \\
\text { frequency }(\mathrm{Hz})\end{array}$ & $h(\mathrm{~m})$ & $\begin{array}{l}\text { Total } \\
\text { days }\end{array}$ & $\mathrm{J}$ & $\mathrm{F}$ & $\mathrm{M}$ & $\mathrm{A}$ & $\mathrm{M}$ & $\mathrm{J}$ & $\mathrm{J}$ & $\mathrm{A}$ & $\mathrm{S}$ & $\mathrm{O}$ & $\mathrm{N}$ & $\mathrm{D}$ \\
\hline \multirow{3}{*}{2012} & \multirow{2}{*}{20} & 10 & 181 & 9 & 8 & 2 & 10 & 24 & 22 & 29 & 23 & 13 & 11 & 15 & 15 \\
& 20 & 170 & 9 & 3 & 1 & 10 & 24 & 21 & 29 & 20 & 13 & 11 & 14 & 15 \\
& 80 & 174 & 9 & 4 & 2 & 10 & 24 & 22 & 29 & 23 & 13 & 11 & 14 & 13 \\
& & 100 & 38 & 6 & 4 & 1 & 9 & 11 & 4 & 0 & 3 & 0 & 0 & 0 & 0 \\
\hline \multirow{3}{*}{2013} & \multirow{2}{*}{20} & 10 & 200 & 27 & 20 & 20 & 27 & 25 & 8 & 23 & 8 & 6 & 10 & 13 & 13 \\
& & 20 & 186 & 25 & 20 & 18 & 27 & 25 & 8 & 23 & 8 & 5 & 5 & 9 & 13 \\
& & 80 & 190 & 22 & 20 & 19 & 25 & 25 & 8 & 23 & 8 & 6 & 9 & 13 & 12 \\
& & 100 & 24 & 0 & 0 & 5 & 9 & 0 & 0 & 0 & 0 & 0 & 0 & 3 & 7 \\
\hline
\end{tabular}

Table 2 Turbulence data availability (in days) at Horns Rev at $50 \mathrm{~m}$ for each month for all years. Also shown are measurement height $h$ and sonic sampling frequency at different periods.

\begin{tabular}{lllllllllllllll}
\hline Year & Sampling frequency $(\mathrm{Hz})$ & $h(\mathrm{~m})$ & $\mathrm{J}$ & $\mathrm{F}$ & $\mathrm{M}$ & $\mathrm{A}$ & $\mathrm{M}$ & $\mathrm{J}$ & $\mathrm{J}$ & $\mathrm{A}$ & $\mathrm{S}$ & $\mathrm{O}$ & $\mathrm{N}$ & $\mathrm{D}$ \\
\hline $1999-2000$ & 20 & & & & & & & & & & & & & \\
$2001-2005$ & 12 & & & & & & & & & & & & & \\
$1999-2005$ & & 50 & 110 & 55 & 85 & 65 & 27 & 0 & 0 & 1 & 5 & 14 & 64 & 72 \\
\hline
\end{tabular}

Climatological 10-min mean cup anemometer data are used to calculate the power spectra for frequencies up to the Nyquist frequency, $0.05 \mathrm{~min}^{-1}$. The spectrum was calculated using the Fourier transform, with a linear detrending applied to the yearly time series. The few missing data in the time series were filled in using linear interpolation with data before and after the gaps. A smoother spectrum is obtained afterwards by averaging the values of the spectral power in bins of $\log _{10} f$, with 25 bins used for each decade. We refer to this as $\log$-smoothing. Good data coverage is important for a reliable calculation of the Fourier spectrum and all time series used herein have a data coverage better than $97 \%$.

In order to obtain the spectral information around the expected gap frequencies, we use the time series from the high frequency sonic measurements with a length of one day, thus covering the spectral gap range and merging with the spectrum from the 10-min measurements at a frequency of about 1 day $^{-1}$.

When calculating the climatological spectrum for high frequencies, only days when missing sonic data $<0.05 \%$ are chosen. For Høvsøre, the number of such 
days in each month is given in Table 1 for each height for the two years considered.

At the Horns Rev site, there are 498 days in total. The incomplete turbulence data coverage and uneven distribution throughout the year may question the climatological representativity in some aspects of the results from these data. This will be discussed further in Sect. 4. The spectrum is calculated from the sonic data using a Fourier transform after applying a linear detrending. We have chosen not to use a Hanning window to the day-long time series, see the Appendix. The log-smoothing is applied. The spectrum for the horizontal and vertical wind speeds, $U$ and $w$, respectively, as well as the cospectrum of $U$ and $w$, were first calculated from each day and averaged afterwards to obtain the mean spectrum and mean cospectrum. In the Appendix we discuss the stationarity conditions required for the calculation of the Fourier tranform using 1-day long time series. To control the possible spectral energy leakage associated with strongly non-stationary conditions, i.e., to avoid the "outliers", when calculating the mean spectrum we used all data at each frequency that satisfy $\langle S(f)\rangle-2 \sigma(S(f))<S(f)<\langle S(f)\rangle+2 \sigma(S(f))$, where $\langle S(f)\rangle$ and $\sigma(S(f))$ are the mean value and standard deviation of $S$ at $f$. This process removed about $5 \%$ of data.

Three wind components over the range from 1 day $^{-1}$ to the Nyquist frequency of the time series, the longitudinal wind $(u)$, the lateral wind $(v)$ and the vertical $(w)$ were also investigated. In order to decompose the horizontal winds into $u$ and $v$, both the wind speed and direction need to be stationary. Days where the wind direction does not vary more than 50 degrees are selected for this purpose. At Horns Rev, the realignment of the sonic with the horizontal wind every $10 \mathrm{~min}$ done in the original preprocessing of the data results in missing information about the lateral wind $(v)$ for scales larger than $10 \mathrm{~min}$. For this reason, the results for the wind components are only from Høvsøre.

\section{Results}

The availability of both standard wind and turbulence measurements at Høvsøre at several levels from $10 \mathrm{~m}$ to $100 \mathrm{~m}$ provides a unique opportunity to examine how the full range velocity spectrum varies with height, including the power spectrum, cross spectrum and the spectral gap. The measurements from Høvsøre and Horns 
Rev together are expected to contribute to our understanding of the spectral behaviour for onshore and offshore conditions.

\subsection{The full-scale power spectrum}

The full range spectra of wind speed from Høvsøre, with $f$ from about $1 \mathrm{yr}^{-1}$ to $10 \mathrm{~Hz}$, are calculated and presented as $f S(f)$ versus $f$ on a log-log scale in Figs. 3 and 4, where the data from 2012 and 2013 are used, respectively. The results from the two years are presented separately in order to show that, even though the data distribution over the year is not the same (Table 1), the results are consistent, suggesting that data from either of the two years are climatologically representative for certain spectral aspects. The spectra are shown at three heights where both the mean wind speed and turbulence data are available, namely $10 \mathrm{~m}$, $80 \mathrm{~m}$ and $100 \mathrm{~m}$. At each height, there are three portions of spectra presented. For the macroscale to mesoscale, the grey curve is from the 1-year long time series of 10-min averaged wind speed. Here we see the large fluctuations caused by the availability of only few data points at the lowest frequencies. To obtain a more climatologically representative spectrum, 10 years of data are used here, which is shown as the black dashed curve. This is consistent with the one-year data, and as expected, the fluctuation of $f S(f)$ is greatly reduced at the frequencies of about $1 \mathrm{yr}^{-1}$ when more data are used. The thin black curves are the average of the spectra calculated from 1-day long time series of $20-\mathrm{Hz}$ wind speed for days as listed in Table 1. The mesoscale to microscale spectra from the turbulence data from four heights are shown together, for 2012 (Fig. 3d) and 2013 (Fig. 4d), respectively. From Figs. 3 and 4, we observe: (1) In general, the spectra based on sonic data converge rather smoothly to the spectra made from the 10min time series, suggesting the consistency between the two data series in their overlapping range. (2) The spectral transition of $f S(f)$ from the microscale to mesoscale suggests a "gap" at $10 \mathrm{~m}$ when $f$ is close to $10^{-3} \mathrm{~Hz}$, but is shown as a plateau at $80 \mathrm{~m}$ and $100 \mathrm{~m}$. Figures 3d and $4 \mathrm{~d}$ suggest a gradual decrease in the gap depth with height. (3) For frequencies higher than the 10-m gap, the turbulence intensity decreases with height, and it is the opposite for frequencies lower than the 10-m gap. (4) There is a narrow peak at $1 \mathrm{yr}^{-1}$ from the 10 -year 
time series. (5) There is a maximum value of $f S(f)$ at about $0.2 \mathrm{day}^{-1}$ for the energy-containing range from $1 \mathrm{yr}^{-1}$ to $1 \mathrm{hr}^{-1}$. (6) There is a narrow peak at 1 day $^{-1}$ at $10 \mathrm{~m}$ height, but not at $80 \mathrm{~m}$ and $100 \mathrm{~m}$.

As in Figs. 3 and 4, the full range spectrum of wind speed is presented in Fig. 5 for the offshore site Horns Rev. To examine the "climatological representativity" of a one-year time series (from 2002) in representing the spectrum, we also selected from the Horns Rev measurements all months from 1999 to 2006 where the data coverage is greater than $99 \%$ and the mean spectrum from all these months (referred to as "the good months" in Fig. 5) is compared to that from 2002. The agreement is good for their overlapping frequency range. For the mesoscale to macroscale, the 10 -min wind speed at $45 \mathrm{~m}$ was used; the turbulence properties were measured at $50 \mathrm{~m}$. Note that in Fig. 5, the increasing spectral energy with frequency at the tail is the folding of higher frequencies, which should be disregarded. In Fig. $6 \mathrm{a}$ and b, the spectra from the 10-min time series at all measurement heights are shown, for Høvsøre and Horns Rev, respectively. According to Fig. $6 \mathrm{~b}$, for the mesoscale range, the difference is negligible between $45 \mathrm{~m}$ and $62 \mathrm{~m}$; we therefore expect negligible difference between $45 \mathrm{~m}$ and $50 \mathrm{~m}$. No "gap" is observed here.

The increase of the power spectrum with height at mesoscales shown by the sonic data is shown again in the 10-min data from Høvsøre, see Fig. 6a. Here we see the land influence in the power spectrum at $10 \mathrm{~m}$ indicated by the clear diurnal peak. This peak becomes weaker with increasing height and indistinguishable at $80 \mathrm{~m}$. Recall that in the Van der Hoven spectrum, there is a missing diurnal peak, a property that has been much discussed. The diurnal peak is documented to be absent for a water site (e.g. for Horns Rev in Fig. 6b and for a number of lightships and small island stations in Troen and Petersen (1989)), but for land sites, the missing diurnal peak was also reported at a height of the order of 70 to $100 \mathrm{~m}$ in a number of studies, e.g. Oort and Taylor (1969) and Petersen (1975). Troen and Petersen (1989) explained that the height at which the diurnal peak becomes small is where the first-order effect of the surface heat flux modulations vanishes and they used this observation to construct the stability correction model. It can be noted that the height at which the minimum amplitude of the diurnal cycle occurs varies with season, being lowest in winter and highest in summer. The amplitude 

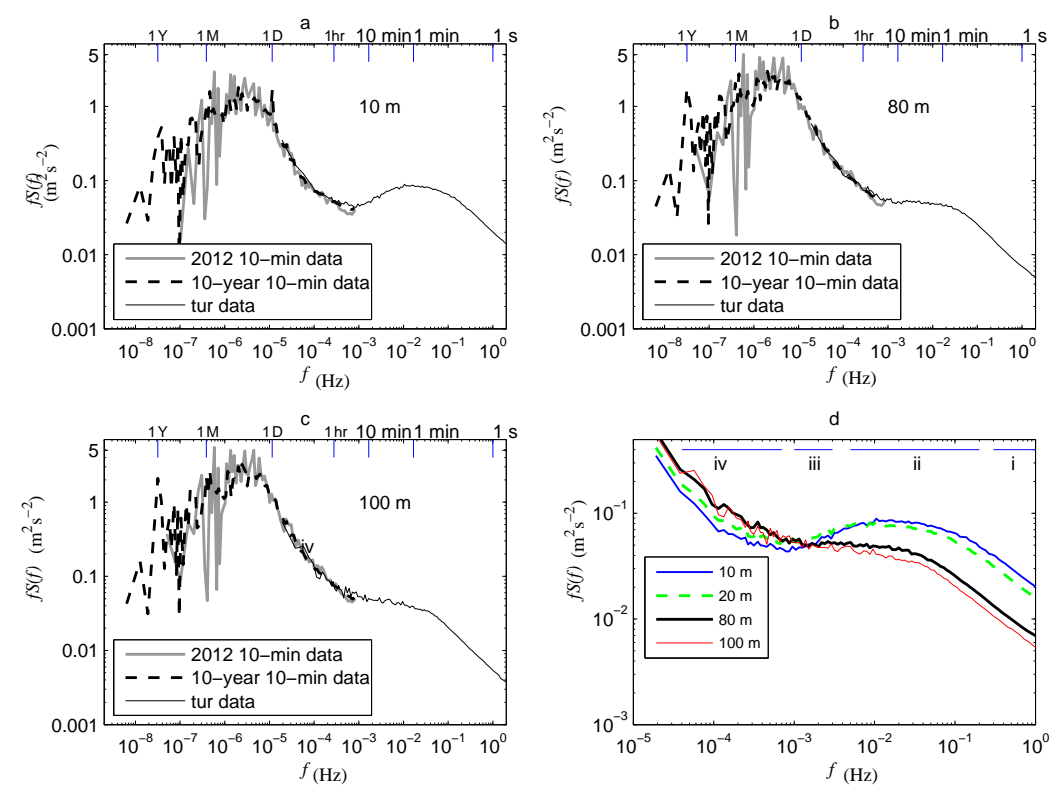

Fig. 3 The spectra of wind speed $f S(f)$ as a function of frequency $f(a)$ : at $10 \mathrm{~m}$, (b) $80 \mathrm{~m}$ and (c) $100 \mathrm{~m}$, (d) at four levels from 10 to $100 \mathrm{~m}$ where data are a 1-day long, 20-Hz time series. All data are from Høvsøre, 2012. (a) to (c) each consists of the spectrum calculated from the 10-min wind-speed time series from the entire year and the spectrum calculated from the sonic time series at the same height of 1-day length. The spectrum from 10 years of 10-min data $(2005$ - 2014) is also plotted. The scales corresponding to 1 year, 1 month, 1 day, $1 \mathrm{hr}, 10$ min, 1 min and $1 \mathrm{~s}$ are marked. The four ranges of Fig.4 in Högström et al. (2002) are shown in $(\mathrm{d})$.

increases with height after the minimum, but it is not well established where the increase fades out or even reverses. The reason for this observation is however unclear; Byzova (1967) found such an increase up to $300 \mathrm{~m}$ and Vinnichenko (1970) even found a diurnal cycle as high as 3 to $20 \mathrm{~km}$. But for the planetary boundary layer it is observed that no diurnal cycle exists in the spectrum for the geostrophic wind calculated by means of surface pressure and temperature observations (Petersen et al. 1981; Larsén and Mann 2006). It can also be noted that a large yearly peak exists in the geostrophic wind spectrum and the surface wind spectra from all stations in Troen and Petersen (1989). Compared to the Høvsøre spectra, in the mesoscale the Horns Rev spectra show negligible height 

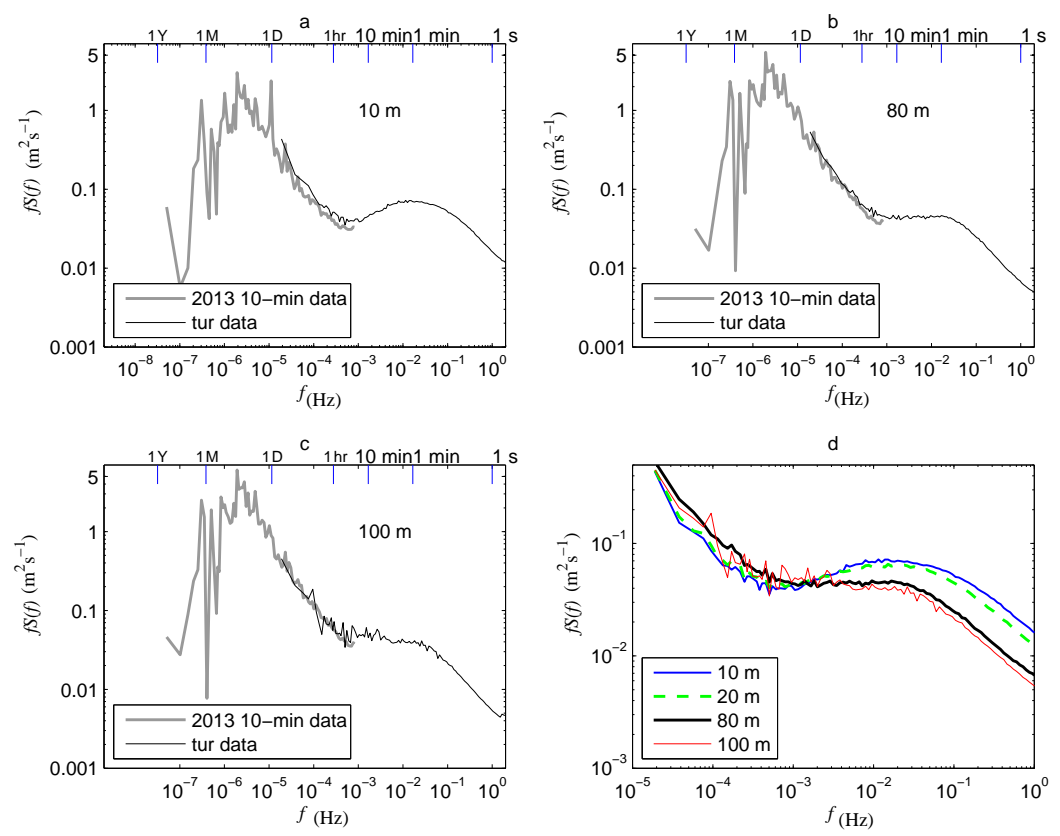

Fig. 4 The notations are the same as Fig. 3, except for 2013, excluding the 10-year spectrum in (a) to (c).

dependence between 15 and $62 \mathrm{~m}$ (Fig. 6b). This could be a result from the impact of surface fluxes becoming insignificant already at $15 \mathrm{~m}$, much lower than over land because of the smooth surface and smaller stability variation. For mesoscale flow, the rougher land surface serves as a stronger sink of momentum, leading to weaker winds and accordingly smaller wind-speed variations. This is reflected as lower wind variations at levels closer to the ground.

We combine the full range spectra from the onshore and offshore sites together for the same height of $50 \mathrm{~m}$; the spectra are shown both in the log-log and the log-linear scale in Fig. 7a and b, respectively. At Horns Rev, there are sonic data at $50 \mathrm{~m}$ and there are 10-min data at $45 \mathrm{~m}$ and $62 \mathrm{~m}$, but not at $50 \mathrm{~m}$. As explained in producing Fig. 5, here 10-min data at $45 \mathrm{~m}$ were used which should give a very similar spectrum to the corresponding one at $50 \mathrm{~m}$. At Høvsøre, there are 10-min data at $60 \mathrm{~m}$ and there are sonic data at $10 \mathrm{~m}, 20 \mathrm{~m}$ and $80 \mathrm{~m}$, but not at 50 $\mathrm{m}$. We use the 10-min spectrum from $60 \mathrm{~m}$, which, according to Fig. 6a, should 


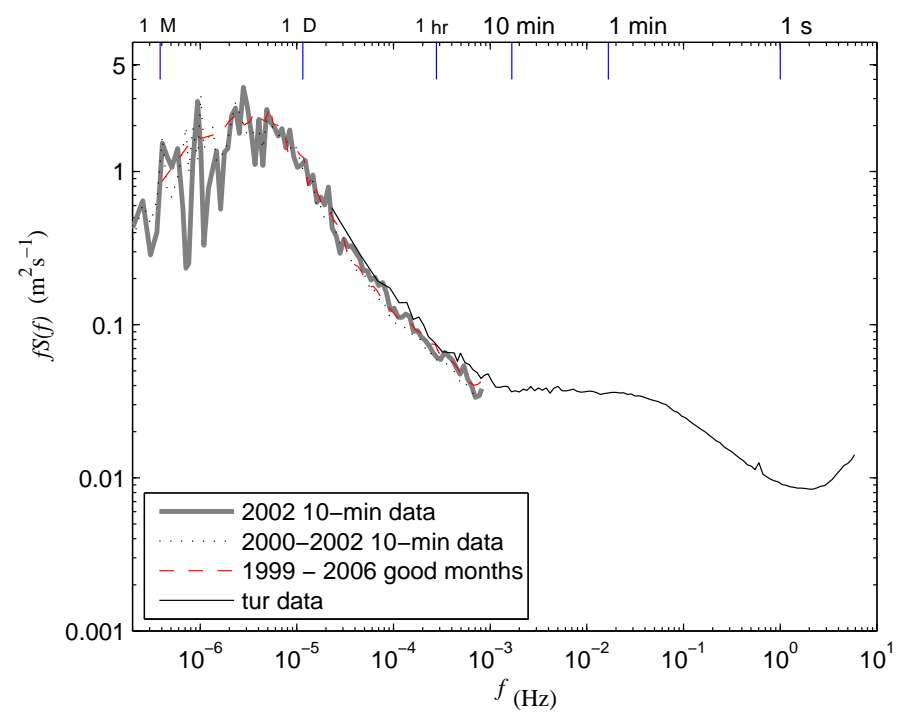

Fig. 5 The spectra of wind speed $f S(f)$ as a function of frequency $f$ at Horns Rev, the thick gray curve is for $45 \mathrm{~m}$ from 10-min cup data, the thin black curve is for a height of $50 \mathrm{~m}$ from sonic data and the red, dashed curve is for a height of $45 \mathrm{~m}$ from 10-min cup data from months of with data coverage larger than $99 \%$.
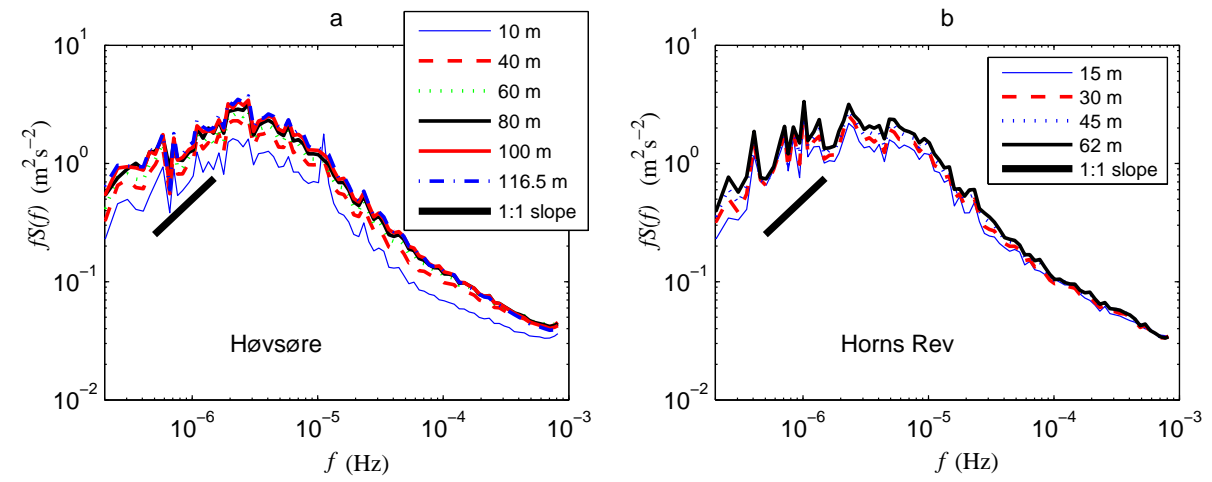

Fig. 6 The spectra of wind speed $f S(f)$ vs. frequency $f$ from a 1-year long, 10-min time series at all measurement heights: (a) Høvsøre; (b) Horns Rev.

be very close to that from $50 \mathrm{~m}$. In order to obtain the spectrum for $50 \mathrm{~m}$ from the sonic data at Høvsøre, we assumed a logarithmic vertical variation of $f S(f)$ as shown in Figs. 3d and 4d. This assumption is encouraged by the test with the spectrum at $20 \mathrm{~m}$. The estimated spectrum at $20 \mathrm{~m}$ under this assumption, 

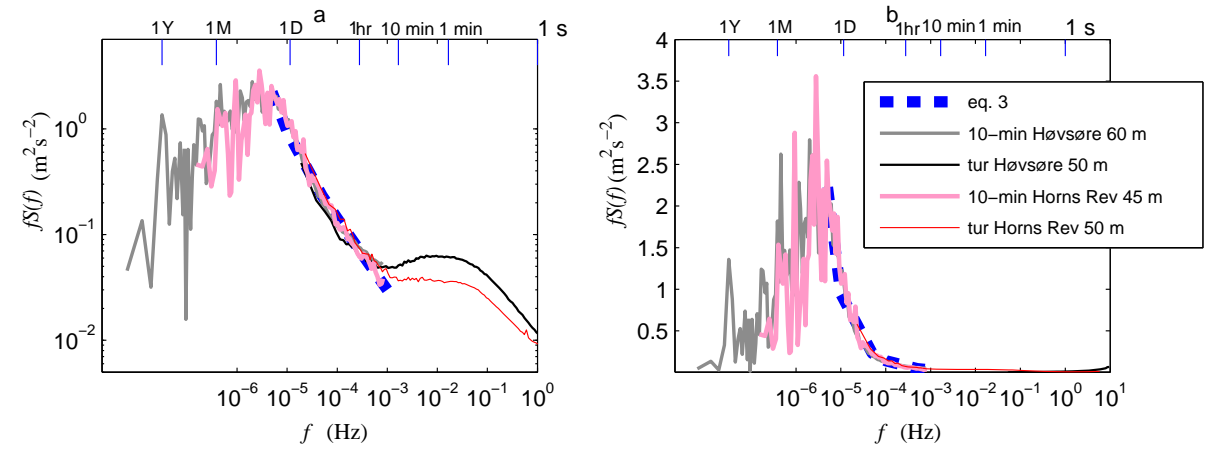

Fig. 7 The onshore (Høvsøre) and offshore (Horns Rev) spectra of wind speed plotted together: (a) in log-log scale (b) in log-linear scale.

using the measurements from $10 \mathrm{~m}$ and $80 \mathrm{~m}$ from both 2012 and 2013, is in good agreement with the directly measured spectrum at $20 \mathrm{~m}$. Both the $10-\mathrm{min}$, mesoscale, spectra from Horns Rev and Høvsøre match satisfactorily with the spectral model Eq. 2, represented as

$$
f S(f)=a_{1} f^{-2 / 3}+a_{2} f^{-2}
$$

with $a_{1}=3 \times 10^{-4} \mathrm{~m}^{2} \mathrm{~s}^{-8 / 3}$ and $a_{2}=3 \times 10^{-11} \mathrm{~m}^{2} \mathrm{~s}^{-4}$. Equation 3 is shown as the dashed (blue) curve in Fig. 7. Seemingly it is a good model for the frequency interval between the possible spectral gap and the macroscale spectral peak at around 5 days. The turbulence spectrum merges smoothly with the corresponding low frequency spectrum. In comparison with the water site, at the same height over land, the microscale turbulence is significantly higher and contributes to the modification of the mesoscale $-2 / 3$ slope to lower frequencies. Over water, the mesoscale $-2 / 3$ slope extends to higher frequencies where it joins the microscale turbulence contribution. Considering the relative position of the estimated Høvsøre spectrum at $50 \mathrm{~m}$ to those at other heights (cf. Figs. 3d and 4d), even with uncertainties due to the assumption of vertical logarithmic variations, the above conclusion remains the same regarding the difference between land and water spectra. 
4.2 The spectral gap

It is noticeable in Figures 3, 4, 5 and 7 that the turbulence spectrum undergoes transition smoothly to the 10-min data spectrum at a frequency of about 0.05 $\min ^{-1}$. But how does the power spectrum from the mesoscale range merge with that from the microscale range?

There have been speculations that the sum of the microscale and the mesoscale spectra results in the total power in the gap range. This idea has often been shown qualitatively, e.g. in Kim and Adrian (1999) and Högström et al. (2002), but has not been proven true due partly to the missing of quantitative description of the mesoscale spectrum. We here follow this hypothesis: as with wave patterns, the two parts linearly superimpose. Results from this study and others (e.g. Nastrom and Gage (1985); Gage and Nastrom (1986); Larsén et al. (2013)) suggest a rather simple spectral behaviour for the mesoscale as shown in Eq. 1 or Eq. 2. For the microscale, the Kaimal spectrum is often used. Here, in line with our hypothesis, we use the Kaimal spectrum for the microscale range for frequencies lower than the peak $f_{p}$. This idea basically borrows the $f^{+1}$ shape of the Kaimal spectrum for $f<f_{p}$ but still uses the measured turbulence for $f>f_{p}$, as demonstrated in Fig. $8 \mathrm{a}$ and $\mathrm{b}$ for $10-\mathrm{m}$ height. Equation 3 is used to represent the mesoscale spectrum; here for the 10-m height. To match the measurements at $10 \mathrm{~m}$ that are affected by the surface (Fig. 6a), the equation is scaled using a coefficient of 0.7 , shown as the dashed (green) line in Fig. 8a and b. The solid (blue) curve, in Fig. $8 \mathrm{a}$ and $\mathrm{b}$, is the average of the 10-m spectra from Figs. 3d and 4d. The Kaimal spectrum for the component $u$ under neutral conditions reads,

$$
\frac{f S_{u}(f)}{u_{*}^{2}}=\frac{A f z / U}{(1+33 f z / U)^{5 / 3}} .
$$

According to this expression, with the use of the logarithmic wind law for neutral conditions, $U=\left(u_{*} / \kappa\left(\ln \left(z / z_{0}\right)\right)\right), A$ can be derived as a function of the roughness length $z_{0}$, height $z$, the peak frequency of the 3D turbulence $f_{p}$ and the corresponding value of $\left.f S_{u}(f)\right|_{f=f_{p}}$. Conventionally, $A=102$. For the present annually averaged spectrum, based on a measured value of $f S_{u}(f)$ at $f_{p}=0.014 \mathrm{~Hz}$, a value of 179 is obtained for $A$ using $z_{0}=0.03 \mathrm{~m}$. Accordingly, $f S_{u}(f)$ can be described 
in terms of $f, f_{p}$ and $\left.f S_{u}(f)\right|_{f=f_{p}}$. For $f<f_{p}$, this is shown as the dotted (black) line in Fig. 8a.

If our hypothesis, that the observed spectrum is a linear superimposition of the mesoscale (dashed line) and the microscale (black dotted line) spectra, is true, then their sum should match the measured total spectrum (the blue solid curve). This is confirmed by the dashed-dotted (red) curve, which is the sum of the dashed and dotted lines as in Fig. 8b.

The same is true for heights of $80 \mathrm{~m}$ and $100 \mathrm{~m}$, as shown in Fig. $8 \mathrm{c}$ and $\mathrm{d}$, respectively. Note, for Høvsøre at $80 \mathrm{~m}$ and $100 \mathrm{~m}$, Eq. 3 was used without being scaled. When the spectral energy from the mesoscale eddies (2D turbulence) is large, the microscale spectral peak can become flat or disappear, as happens at 80 $\mathrm{m}$ and $100 \mathrm{~m}$. This makes it difficult to determine $f_{p}$ and hence where to apply the Kaimal spectral shape for the $f^{+1}$ dependence. Here, by eye fitting, $f_{p}=0.01$ $\mathrm{Hz}$ and $0.009 \mathrm{~Hz}$ were used for $80 \mathrm{~m}$ and $100 \mathrm{~m}$, respectively.

With this theory we can explain why the most dominant gap is observed at lower levels and sometimes becomes insignificant at higher levels, and why the gap is clearer over land than over water at the same height. It depends on the relative contribution of the mesoscale and microscale power energy. For instance, at Høvsøre, compared to $80 \mathrm{~m}$ and $100 \mathrm{~m}$, at $10 \mathrm{~m}$, the 3D turbulence is stronger but the $2 \mathrm{D}$ mesoscale variation is smaller, and this leads to a more visible gap at $10 \mathrm{~m}$. At the same height, e.g. $50 \mathrm{~m}$, the mesoscale spectra are comparable for Høvsøre and Horns Rev and they are substantial compared to the 3D turbulence in the gap range, resulting in almost invisible gaps at both sites. At this height, since the $3 \mathrm{D}$ turbulence at Horns Rev is considerably weaker than that at Høvsøre, the "gap" at Høvsøre is very shallow but distinguishable (Fig. 7a), but it is invisible at Horns Rev.

4.3 The three wind components

From the same datasets from Høvsøre as used in Figs. 3d and 4d, the spectra of the vertical wind component, $w$, were calculated from 1-day long time series for four heights, $10 \mathrm{~m}, 20 \mathrm{~m}, 80 \mathrm{~m}$ and $100 \mathrm{~m}$ and the results are shown in Fig. 9a and $\mathrm{b}$ for the years 2012 and 2013, respectively. The results from the two years are 

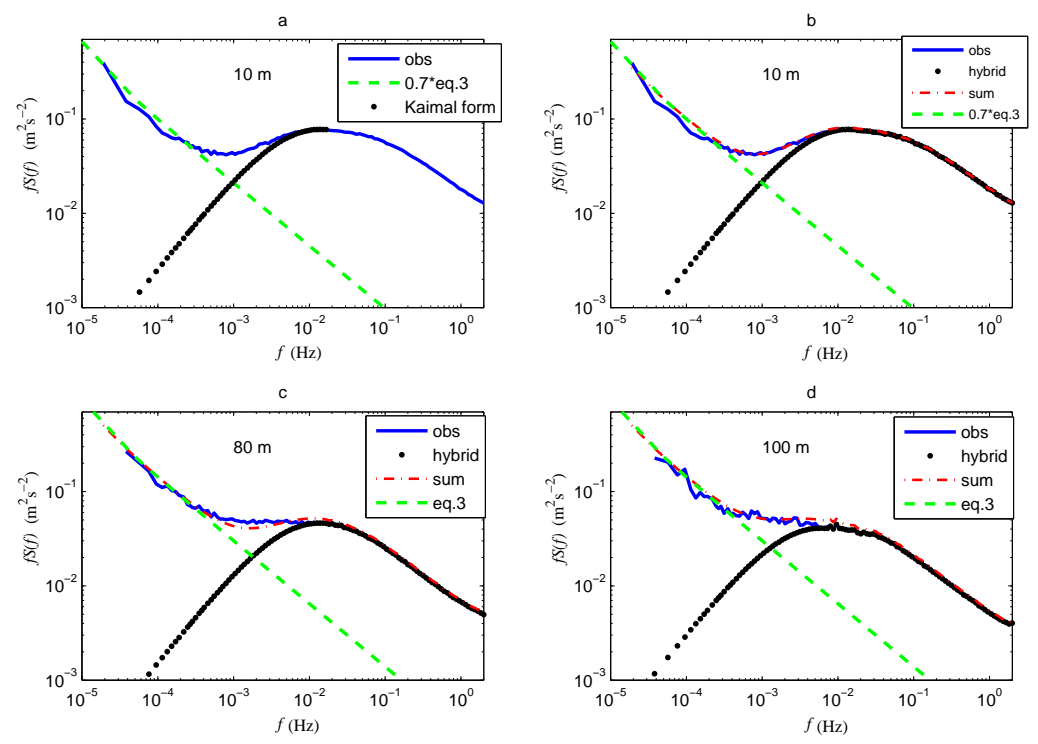

Fig. 8 Superimpose of the spectral components. (a) at $10 \mathrm{~m}$, measured spectrum together with the spectral model Eq. 3 multiplied by 0.7, extending to high frequencies, and a Kaimal spectrum for frequencies lower than the peak frequency. (b) at $10 \mathrm{~m}$, the sum of the mesoscale spectrum with a slope of $-5 / 3$ and the microscale spectrum with the shape of a Kaimal model (the red curve) gives the observed spectrum. (c) The same as (b) but for $80 \mathrm{~m}$. (d) The same as (b) but for $100 \mathrm{~m}$.

again almost the same. With increasing height, the spectral peak moves to lower frequencies, and the energy level decreases slightly with height. From Fig. 9 one could notice that towards the lowest frequencies, $f S(f)$ for $w$ at several heights seems to increase with decreasing frequency. This could be an artifact caused by the sensitivity of the sonic measurements of $w$ : when using such a long time series of $w$ for Fourier transform, the slightest misalignment of the sonic could cause the contamination of $w$ from the component $u$ at all frequencies, but only noticeable at the low frequencies. This effect is expected to be more pronounced when the wind field is more unsteady. The longer the time series, the larger is the chance for unsteady flow. This speculation is supported by Fig. 10, for which we only selected days from Table 1 where the wind direction changes less than 50 degrees during a day. The increase of the power spectrum of $w$ with decreasing frequency as shown in Fig. 9 is significantly reduced in Fig. 10. 
Choosing days with relatively small direction variation $\left(<50^{\circ}\right)$ is for the purpose of obtaining the longitudinal and lateral wind components, $u$ and $v$, from the one-day long time series of the wind speed and the daily mean direction. There are 100 days from 2012 and 2013 (Table 1) satisfying this criterion for $10 \mathrm{~m}, 20 \mathrm{~m}$ and $80 \mathrm{~m}$ but only 34 days at $100 \mathrm{~m}$. The spectra for the three wind components $u, v$ and $w$ are shown in four subplots in Fig. 10 for four heights, $10 \mathrm{~m}, 20 \mathrm{~m}, 80 \mathrm{~m}$ and $100 \mathrm{~m}$, respectively. In the 3D inertial subrange, we observe that $v$ and $w$ have comparable level of energy, both greater than that of the $u$ component, a classical behaviour. Consistent with the classical 3D turbulence theory, the peak frequency for $w$ is seen to be the highest, and for $u$ it extends to the lowest frequencies.

With the contribution from the mesoscale spectrum, the power spectra for both $u$ and $v$ increase with decreasing frequency in the mesoscale range and the energy level for $u$ is comparable to that for $v$, consistent with Larsén et al. (2013) based on 1-day long 10-min mean data from several years of data at Nysted and Horns Rev sites. They found that the ratio of the spectra for $u$ and $v$ is on average $<1$ when $f<10^{-4} \mathrm{~Hz}$ but is greater than 1 , reaching 1.2 when $f$ increases and approaches $0.05 \min ^{-1}$ (their Fig. 7). Further, the observed zero correlation between $u$ and $v$ supports the 2D isotropy hypothesis in this mesoscale range, and so does the behaviour of $u$ and $v$ for $f<10^{-4} \mathrm{~Hz}$. However, the relatively larger $u$ spectrum than $v$ spectrum in the range $2 \times 10^{-4}<f<0.8 \times 10^{-3} \mathrm{~Hz}$ contradicts the isotropy assumption (Frehlich and Chelton 1986). Figure 10 provides us with a wider picture of the spectral behaviour in this complicated range. For $f<2 \times 10^{-4} \mathrm{~Hz}$, the $u$ spectrum is smaller than the $v$ spectrum, with a ratio on average about 0.8 , consistent with Larsén et al. (2013). The consistency is also true for the relatively larger values of the $u$ spectrum in $2 \times 10^{-4}<f<0.8 \times 10^{-3} \mathrm{~Hz}$, which the current study suggests is caused by the impact from $3 \mathrm{D}$ turbulence. As shown in both Figs. 9 and 10, the $w$ component energy approaches zero as $f$ approaches the mesoscale, suggesting the $2 \mathrm{D}$ nature of the relatively large-scale flow.

\subsection{The cospectrum}

From the same datasets from Høvsøre as used in Figs. 3d, 4d and 9, the cospectra of wind speed $U$ and the vertical wind $w$ were calculated for the four heights from 

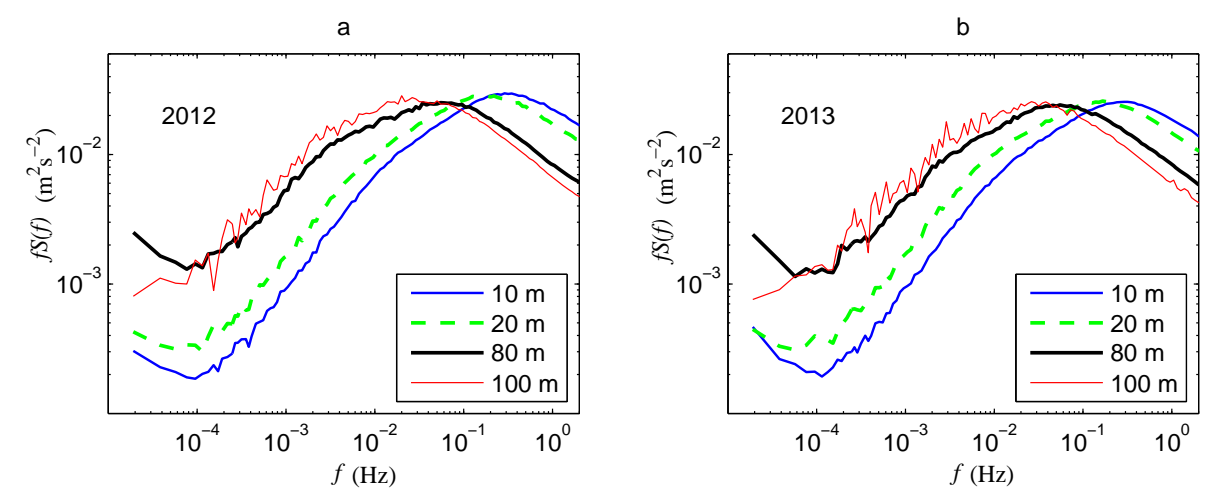

Fig. 9 The spectra of the vertical wind component $(w) f S(f)$ vs. frequency $f$ from 1-day long, 20-Hz time series at four heights at Høvsøre: (a) from year 2012; (b) from year 2013.
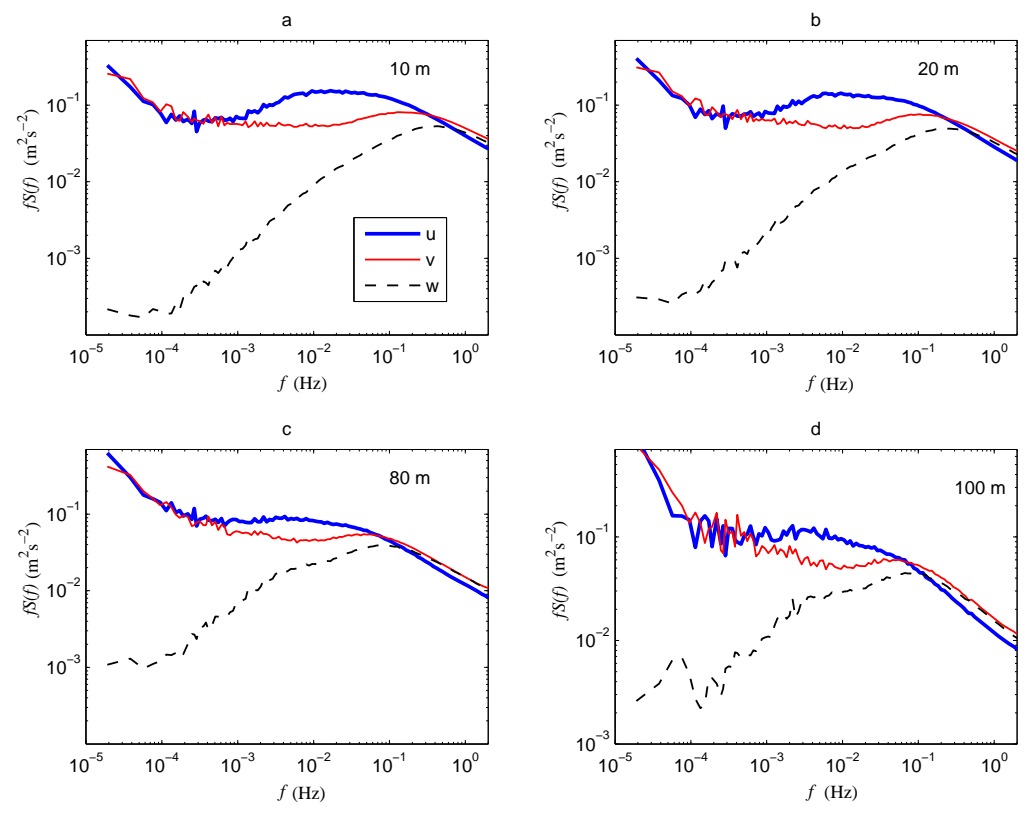

Fig. 10 The three components $u, v$ and $w$ from days where the daily directional change is less than 50 degrees. (a) $10 \mathrm{~m}$; (b) $20 \mathrm{~m}$; (c) $80 \mathrm{~m}$; (d) $100 \mathrm{~m}$. 

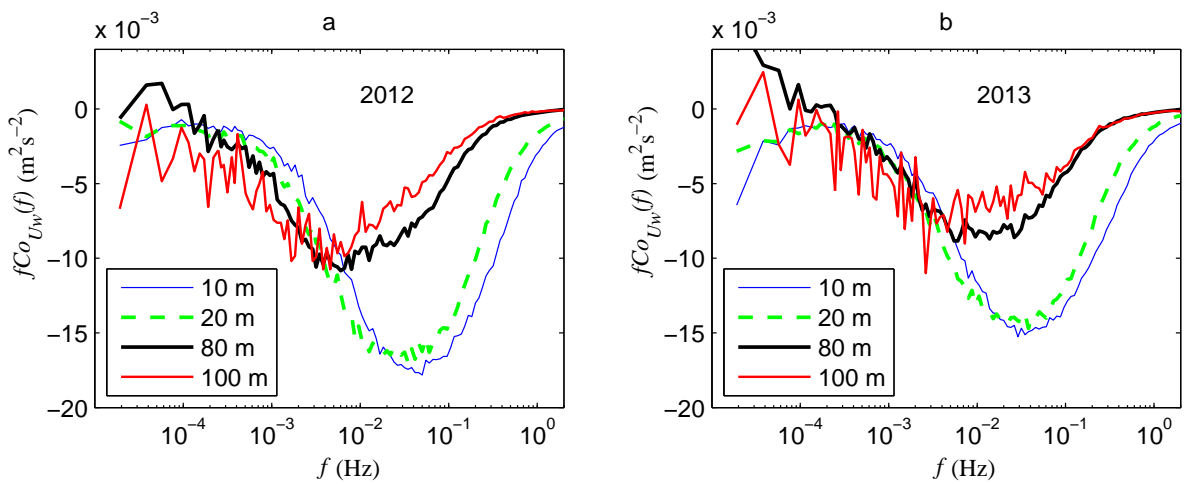

Fig. 11 The cospectra of wind speed and the vertical wind component $f C o_{U w}(f)$ vs. $f$ from 1-day long $20 \mathrm{~Hz}$ data at four heights at Høvsøre. (a) from year 2012; (b) from year 2013.

$10 \mathrm{~m}$ to $100 \mathrm{~m}$. The results are shown in Fig. 11a and b for the year 2012 and 2013, respectively. The wind speed $U$ is used instead of the $u$ component of the wind in order to make best use of the large dataset and at the same time to avoid the issue with non-stationary time series when dividing $U$ into $u$ and $v$ components for a long time series. ${ }^{1}$

Our day-long time series show the classic spectral behaviour of the energycontaining range where most covariance is contained. This range shifts to lower frequencies as the height increases, and so does the peak frequency. Our data show further that, at heights of $10 \mathrm{~m}$ and $20 \mathrm{~m}, C_{U w}$ becomes small at a frequency of $10^{-3} \mathrm{~Hz}$, but at $80 \mathrm{~m}$ and $100 \mathrm{~m}$ it still has a considerable magnitude. Note that the fluctuations at the lowest frequencies have the same uncertainty as the power spectrum for $w$ (Fig. 9).

The cospectrum of $u$ and $w, C o_{u w}$, has also been calculated using the data as in Fig. 10 (not shown). However, since the data sample size is only $1 / 4$ of those in Fig. 11, we expect the result to be less climatologically representative and more case-sensitive. However, the spectral behaviour of $C o_{u w}$ from 100 days of stationary wind is similar to $\mathrm{Co}_{U w}$.

\footnotetext{
${ }^{1} U=\sqrt{\left(\bar{u}+u^{\prime}\right)^{2}+\left(\bar{v}+v^{\prime}\right)^{2}} \approx\left(\bar{u}+u^{\prime}\right)\left(1+\frac{v^{\prime 2}}{2\left(\bar{u}+u^{\prime}\right)^{2}}\right)=\bar{u}+u^{\prime}+\frac{v^{\prime 2}}{2 \bar{u}}-\frac{v^{\prime 2} u^{\prime}}{2 \bar{u}^{2}}$. Multiplying $w^{\prime}$ both sides and averaging them gives $\overline{U^{\prime} w^{\prime}}=\overline{u^{\prime} w^{\prime}}+\frac{\overline{v^{\prime 2} w^{\prime}}}{2 \bar{U}}-\frac{\overline{v^{\prime 2} u^{\prime} w^{\prime}}}{2 \bar{U}^{2}}$. Considering the overall small values of the second and third terms on the right-hand side of the above equation, the cospectrum of $U$ and $w$ is considered very similar to that of $u$ and $w$.
} 
5 Discussion

Power spectra and cospectra for horizonal and the vertical wind components were computed for the frequency interval between about $1 \mathrm{yr}^{-1}$ to several $\mathrm{Hz}$. We have focused on two sites in the same region, one offshore site in the North Sea about $20 \mathrm{~km}$ from the west coast of Denmark and one coastal site less than $2 \mathrm{~km}$ from the shore line. Data used for the calculation of the spectra include 10-min mean wind speed from cup anemometers and direction for a period of 10 years and sonic anemometer measurements at $20 \mathrm{~Hz}$ or $12 \mathrm{~Hz}$ from periods within these years. The continuous long-term 10-min wind data with good coverage are used to obtain the spectra from about $1 \mathrm{yr}^{-1}$ to $0.05 \mathrm{~min}^{-1}$. The sonic data are used separately for 1 day $^{-1}$ to $6 \mathrm{~Hz}$ or $10 \mathrm{~Hz}$ (Nyquist frequency of the $12 \mathrm{~Hz}$ and $20 \mathrm{~Hz}$ data, respectively). The two datasets provide an overlapping spectral interval from 1 day $^{-1}$ to $0.05 \mathrm{~min}^{-1}$.

There are only about half of the days during a year for which the coverage of the sonic data is more than $99.95 \%$, which is used to qualify the days to be used for the calculation of the spectra (see Sect. 3). It is noted that the incomplete coverage as well as uneven distribution of turbulence data throughout the year make it less conclusive about the absolute level of energy regarding the power spectrum and cospectrum in a climatological sense. However, the parallel calculations, with one using data in Table 1 (results in Sects. 4.1 and 4.4) and one using stationary time series (results in Sect. 4.3), have all shown consistent spectral behaviour.

The new findings give rise to the following discussion topics:

\subsection{On the power spectrum}

In this study we defined four ranges to cover the full-range spectrum: macroscale $\left(f \lesssim 1\right.$ day $\left.^{-1}\right)$, mesoscale $\left(1\right.$ day $\left.^{-1} \lesssim f \lesssim 2 \times 10^{-4} \mathrm{~Hz}\right)$, gap range $\left(2 \times 10^{-4} \lesssim\right.$ $\left.f \lesssim 2 \times 10^{-3} \mathrm{~Hz}\right)$ and microscale $\left(f \gtrsim 10^{-3} \mathrm{~Hz}\right)$. For each range, the current study provides new insights into the spectral behaviour. It is noted that the observed, climatological spectrum of boundary-layer winds from the two Danish sites represent a mid-latitude strong wind regime, and this might limit its universality. 
We observe a peak at $f=1 \mathrm{yr}^{-1}$, which has also been shown with decadeslong time series from mid-latitudes, e.g., in Troen and Petersen (1989) and Larsén and Mann (2006). All spectra calculated from the 10-min anemometer data show another property that shapes the macroscale velocity spectrum: the broad peak at a frequency of about 0.25 to $0.2 \mathrm{day}^{-1}$. This peak is also present in the Van der Hoven spectrum, in Troen and Petersen (1989) and in Baker (2010), from numerous measurements over Europe. Analysis of the 10-min averaged wind time series from Høvsøre shows that the autocorrelation coefficient of the wind speed, $\rho$, decreases with the time lag $\tau$, and becomes almost zero at $\tau \approx 4$ to 5 days, corresponding to the frequency where $f S(f)$ is a maximum. This suggests that the peak is related to synoptic weather processes.

Concerning the processes behind the spectra reported herein, we consider the 3D boundary-layer turbulence to be rather well understood, but for lower frequencies there is not a consistent theory. However, in Larsén et al. (2013), the power law that describes the velocity spectrum in the frequency range $10^{-5} \mathrm{~Hz}$ to $10^{-3}$ $\mathrm{Hz}$, reproduced here as Eqs. 2 and 3, was successfully derived from both the tropospheric wavenumber spectrum of Lilly and Petersen (1983), Nastrom and Gage (1985), Gage and Nastrom (1985), and Lindborg (1999), as well as from a universal saturation spectrum for internal tropospheric gravity waves by Fritts and van Zandt (1987). The height variation of the low frequency spectrum in Fig. 6 indicates that most of the height variation over land takes place below $50 \mathrm{~m}$, implying the coefficients $a_{1}$ and $a_{2}$ in Eqs. 2 and 3 are height-dependent below this height. There is almost no variation with height over sea (here at Horns Rev) above the first measuring height $15 \mathrm{~m}$.

In the transition range between mesoscale and microscale, the nature of the interaction of the 2D and 3D turbulence is not fully understood, and it is in this range where the debate on the existence of gap is ongoing. Figure 8 shows the existence of the gap. The gap is most clear at low levels where the surface impact is most significant and it seems to disappear at higher levels. But the gap being visible or not, the gap region can be modelled, if we assume that the $3 \mathrm{D}$ turbulence and the $2 \mathrm{D}$ mesoscale variations are uncorrelated. Then the total spectrum can be recovered by adding the spectra related to the two phenomena, presented in Fig. 8, assuming for simplicity that the horizontal 3D turbulence follows a neutral Kaimal 
spectrum shape for $f<f_{p}$ and that the mesoscale spectra can be extrapolated to higher frequencies. In a similar approach, Larsen et al. (1990) found the spectrum to be dominated by the mesoscale form for $f$ up to $10^{-2} \mathrm{~Hz}$ for cases with weak 3D turbulence.

The establishment of the mesoscale spectrum has made it possible for us to demonstrate the gap quantitatively. It has also been useful for validating mesoscale modelling (Skamarock 2004). It has been further applied for extreme wind estimation by introducing expected wind variability to the modelled time series that suffers from numerical smoothing effects (Larsén et al. 2012; Larsén and Kruger 2014). This application so far is limited to the mesoscale. The description of the spectrum covering the mesoscale, the gap region and the microscale, as shown herein, provides a possibility for extending such an application for extreme winds to higher frequencies. Wyngaard (2004) argues that neither the ensemble mean models nor the large eddy simulation is appropriate in reproducing the significant fluxes and energy transfer in the so-called Terra Incognita between the inertial subrange and the mesoscale range. The results from our study illustrate spectral aspects of Wyngaard's Terra Incognita.

5.2 On the stationary conditions for the time series

In the full-scale spectrum, two frequency ranges are discussed where $f S(f)$ varies with $f^{+1}$. The first range is at the lowest frequencies (Fig. 6) and the second range is at the high frequency end of the gap approaching the 3D turbulence (Fig. 8).

The first range is seen as an indication that the annual wind time series can be considered to satisfy the stationarity condition as expected for random processes to be ergodic according to the Wiener-Khintchine theorem. This then ensures the credibility of using a Fourier transformation to the year-long time series.

In boundary-layer studies, the often-used data length for calculating the turbulence variance and fluxes is 10 to $30 \mathrm{~min}$. In addition, to counteracting the leakage of low frequency energy into the spectrum, a detrending process and a Hanning window are normally applied routinely to the time series. Looking at the power spectra of the wind speed and $w$ and the cospectrum at 10-m height, Figs. 3a, 4a, $9,10 \mathrm{a}$ and 11 , a time series length of $10 \mathrm{~min}$ is reasonable for including variations 
and co-variations for this height. However, as height increases and the spectral power shifts systematically to lower frequencies, we would expect a longer time series needed to include the relevant information, as pointed out by e.g. Lenschow et al. (1994) and Vickers and Mahrt (2002). In order to understand the spectral behaviour around the "gap" and at larger scales, the time series should be taken longer than the conventionally used 10 - $30 \mathrm{~min}$. In the current study, 1-day time series are used for the Fourier transformation with detrending; the reasons for not applying a Hanning window to such a long time series are given in the Appendix. Accordingly, at the low frequency end of the 1-day time series, $f S(f)$ follows the mesoscale spectrum with a $-2 / 3$ slope, while not as described in the standard theory (e.g. the Kaimal model) with $f S(f)$ varying with $f^{+1}$ because implicitly a gap is assumed and with no consideration of larger scale variations. The organized spectral energy adding in from the mesoscale distinguishes it from the stochastically stationary process as expected from the Wiener-Khintchine theorem. The good matching of the average one day-long sonic data with the 10-min mean data in the overlapping range suggests the appropriateness and robustness of our approach.

\subsection{On the coherence}

We have compared the coherence functions for horizontal displacement for the 3D boundary-layer wind field and the mesoscale wind field, based on 10-min averages:

$$
\operatorname{Coh}(f, \Delta)=\exp \left(-a_{\Delta} \frac{f \Delta}{U}\right)
$$

where $\Delta$ is the separation and $a_{\Delta}$ is a numerical coefficient; $\Delta=\Delta y$ corresponds to a lateral separation relative to the wind direction, while $\Delta=\Delta x$ corresponds to a longitudinal separation. For $3 \mathrm{D}$ boundary-layer turbulence, $a_{\Delta y} \approx 60$ and $a_{\Delta x} \approx 7$ (Panofsky and Dutton 1984). The much smaller value for the longitudinal separation reflects the partial validity of Taylor's hypothesis for longitudinal coherence ( $a_{\Delta x}=0$ corresponds to Taylor's hypothesis being ideally true). For the mesoscale fluctuations, Larsén et al. (2013) and Vincent et al. (2013) find $a_{\Delta y} \approx 7.7$ and $a_{\Delta x} \approx 5$, meaning that the mesoscale coherence functions are much less sensitive 
to the separation direction than 3D boundary-layer turbulence and as coherent as 3D boundary-layer turbulence along the longitudinal direction.

5.4 On the two-dimensional isotropy

The current study (Sect. 4.3) complements the study of Larsén et al. (2013) on the $2 \mathrm{D}$ isotropic characteristics of the mesoscale spectra. In the range from about $10^{-5} \mathrm{~Hz}$ to about $2 \times 10^{-4} \mathrm{~Hz}$, the magnitude of the spectrum of $u$ to that of $v$ is on average 0.8 and the coherence of $u$ and $v$ is zero, consistent with the $2 \mathrm{D}$ isotropic assumption. The current study suggests that the value of the ratio increases with frequency in the gap range caused by a relatively larger contribution from $u$ than $v$ from the 3D boundary-layer turbulence.

Larsén et al. (2013) show that the 2D isotropy characteristics disappear in the presence of organized structures such as convective open cells (see their Figs. 11 and 13). Their Fig. 11 shows that open cells contribute significant energy in the high frequency part of the mesoscale range, where the spectrum is in transition to microscale turbulence. The mean spectrum corresponding to the open cells from Fig. 11 in Larsén et al. (2013) is reproduced here and plotted together with the full-scale spectrum from the Horns Rev site (see the thick black curve in Fig. 12). Among the 18 days with open cells used for producing their Fig. 11, there are two days (day 55 and 56 in 2004) where the sonic data at Horns Rev are available. The two spectra, from each of the two days, are also plotted in Fig. 12. The two individual cases do contribute significant wind variation in the range from about $10^{-4} \mathrm{~Hz}$ to about $3 \times 10^{-3} \mathrm{~Hz}$, especially cell case 2 . Here due to the special wind and stability conditions of the individual cases, the microscale spectrum is enhanced relative to the climatological mean.

\section{Conclusions}

The analysis of long-term mean wind and turbulence data from two sites in Denmark, one onshore and one offshore, has improved our understanding of the fullscale boundary-layer wind spectrum in mid-latitudes. The findings provide guide- 


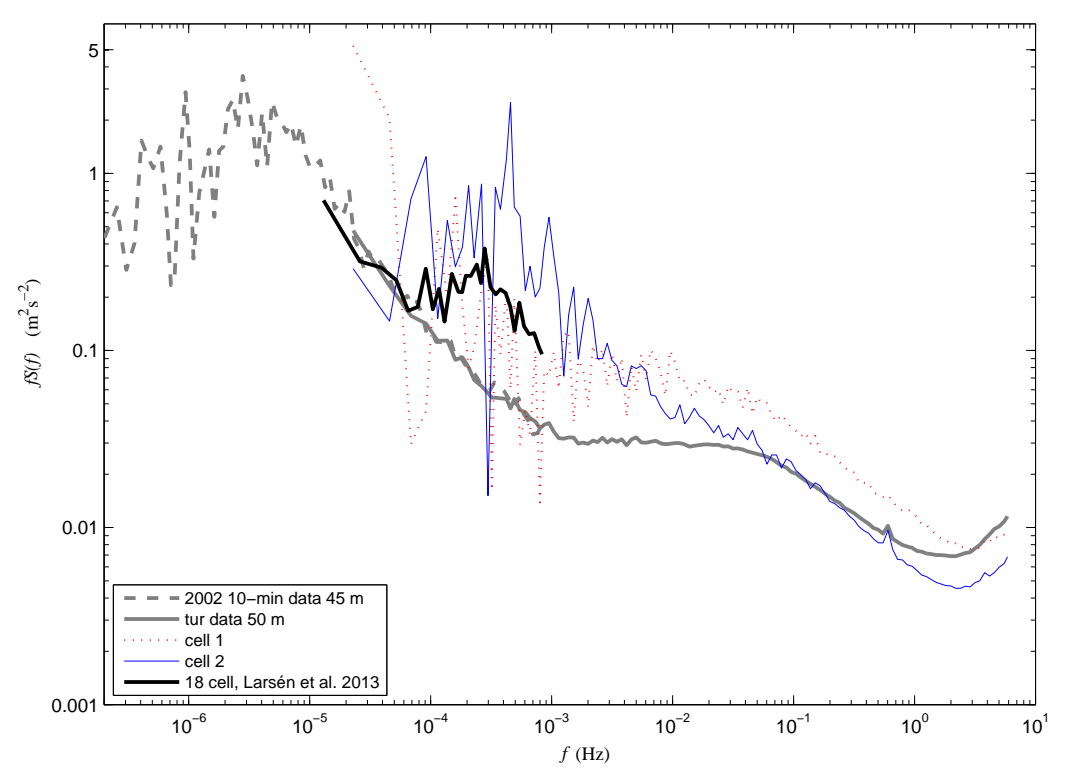

Fig. 12 The spectra of wind speed at the Horns Rev site from two cell case days, together with the mean spectrum of 18 cell case days from Larsén et al. (2013) and the climatological spectrum.

lines for numerical modelling, turbulence analysis and wind engineering applications. This can be summarized as follows,

- The spectral gap in the horizontal wind component power spectrum exists and can be modelled. The linear composite of the wind variations from the mesoscale and microscale gives the observed power spectrum in the gap range. This suggests that the turbulence from the two frequency regions are weakly correlated.

- Depending on the relative contribution to the variation from the microscale and mesoscale, the gap may be visible or invisible. The depth of the gap decreases with height, in general. The disappearance of the gap could also be caused by structured features such as open cells, which can contribute significant fluctuations in this frequency range. The spectral structure around the gap could be used for defining "natural" time windows for turbulence characteristics. 
- For spatial scales larger than the gap, in the range from about $10^{-5} \mathrm{~Hz}$ to about $10^{-3} \mathrm{~Hz}$, the turbulence is two-dimensional. The power spectra $S(f)$ of the wind speed and its two components $u$ and $v$ increase with decreasing frequency, following a $-5 / 3$ dependence on frequency on a log-log scale. In this scale range, $S(f)$ increases from the ground and levels off at a height $\approx 50 \mathrm{~m}$ at Høvsøre, but $<15 \mathrm{~m}$ at Horns Rev. Our study indicates that, on average, it is possible to describe the boundary-layer turbulence (spectral range $i-i i i$ as in Högström et al. (2002), Fig. 3d) as being limited by a $f^{+1}$ behaviour at low frequency, and being statistically stationary and ergodic, at least within the surface layer. Above this layer the assumption is more uncertain, and depends on how one understands and models the "invisible gap". However, also in the surface-layer situations, stationarity cannot always be assumed, as is well-known by meteorologists and illustrated here in Fig. 12 .

- Winds in the mesoscale frequency range seem more spatially coherent than winds in the 3D turbulence range, as measured by Eq. 5 .

Acknowledgements The first author acknowledges the support from the Center for Computational Wind Turbine Aerodynamics and Atmospheric Turbulence, funded by the Danish Council for Strategic Research with grant no. 09-067216. We thank our colleagues Ameya Sathe for advices in using the sonic data, Leif Kristensen, Mike Courtney, Ib Troen and Claire Vincent for valuable comments and discussions.

\section{Appendix 1 The impact of using one-day sonic data to calculate the} spectrum

The turbulence spectra have been calculated with 1-day long sonic data from days as listed in Table 1 and 2. This procedure ensures a detailed description of the spectral regions in and around the gap. However, it raises some issues about the statistics of the established spectra. The daily spectrum can obviously not be considered an analysis of a stationary series, because (a) the wind during the day typically undergoes a systematic diurnal variation, and (b) the low frequency region of the spectrum shows a $f^{-2 / 3}$ power law, which is far from the $f^{+1}$ power law required by the Wiener-Khintchine theorem for possible stationarity. We refer to the spectrum as $f S(f)$ vs. $f$ on a $\log$-log scale. 
In spite of this, we may claim that the $f^{+1}$ spectral region of the annual spectrum $\left(f \lesssim 2 \times 10^{-6} \mathrm{~Hz}\right.$, see Fig. 6) provides good reasons for expecting a yearly-averaged diurnal spectrum to be determined for frequencies $>1$ day $^{-1}$, if a large enough ensemble of diurnal data series are analyzed in the spectral domain for the year considered.

However, given the spectral slope of $f^{-2 / 3}$ at frequencies around 1 day $^{-1}$, the low frequency region of the spectra, from averaging spectra for the day-long time series, is enhanced by leakage of energy from lower frequencies. This enhancement will not disappear by ensemble averaging; hence, it has to be counteracted. This is usually performed by applying windows, such as Hanning and Hamming windows, imposing a sinusoidal window onto the time series (Kristensen et al. 1992; Kristensen 1998). Unfortunately, for the present time series typically associated with diurnal stability variations, the application of a window would modify the relative weight of the different stability classes. Therefore the window method was not used.

Instead, we have tried to control the leakage by excluding cases where the spectral amplitude is beyond the two standard deviations of all spectra. These cases have shown excessive characteristics, mostly associated with large and narrow gust or strongly non-stationary conditions. All together, there are 20 days of such conditions.

For comparison, a spectrum from a 5-day long time series is calculated and shown as the blue circles in Fig. 13. At the same time, a spectrum from each of the five days was also calculated and the five spectra were averaged afterwards and are shown as dots in the same plot. The good agreement between the circles and the dots suggest that there is no principle problem in using 1-day time series for calculating the spectrum. The inertial subrange spectral values for the 5-day spectrum is slightly, but systematically, larger than the similar one for the 1day spectrum. To explain this, we assume that the frequency spectrum is mainly a wavenumber spectrum being advected past the sensor by a "fluctuating mean wind". The variance of this fluctuating advection flow will be larger for the 5-day series than for any of the 1-day series. This would enhance the measured 5-day spectrum slightly more than the 1-day spectrum, following the model of Wyngaard and Clifford (1977) for Taylor's hypothesis with a fluctuating advection wind. 


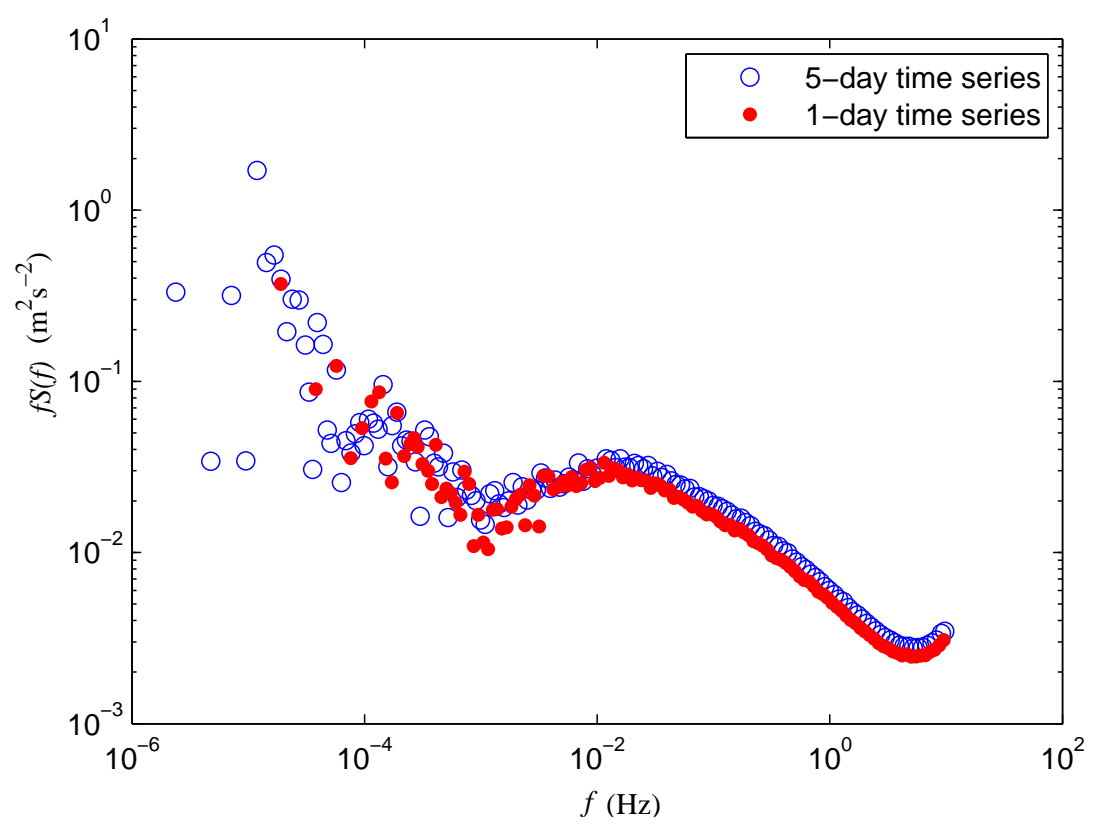

Fig. 13 The power spectrum $f S(f)$ from a five-day long time series together with the mean of five spectra calculated from each of the five days.

Finally in Fig. 14 we show the spectra with all sonic data in Table 1 (the dashed curves) together with those with outliers removed (solid curves, same cases as from Figs. 3d and 4d). The higher values of the dashed curved are seen as the leakage caused by days corresponding to highly non-stationary conditions. Apart from the magnitude, the distribution of the spectra with height remains the same.

\section{References}

Atkinson B (1981) Meso-scale Atmospheric Circulations. Academic Press Inc. London, 495 pp Baker C (2010) Discussion of The macrometeorological spectrum - a preliminary study by R.I. Harris. J Wind Eng Ind Aerodyn 98:945-947

Byzova NL (1967) Characteristics of the wind velocity and temperature fluctuations in the atmospheric boundary layer, in Proceeding of the International Colloquium on Atmospheric Turbulence and Radio Wave Propagation. Moscow . Publishing House Nauka, Moscow Courtney M, Troen I (1990) Wind speed spectrum for one year of continuous $8 \mathrm{hz}$ measurements. Nineth Symposium on Turbulence and Diffusion, American Metrorol Society pp 301-304 


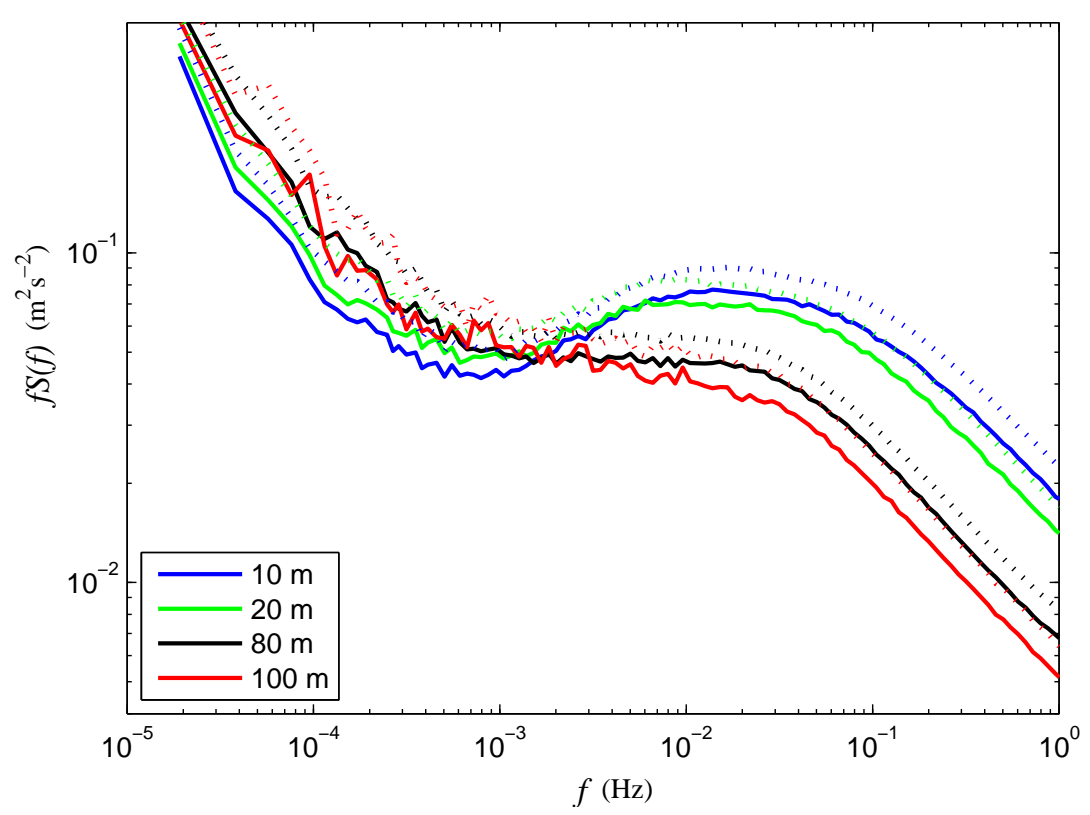

Fig. 14 Power spectra from both 2012 and 2013 (Figs. 3d and 4d together), with outliers excluded (solid curves) and included (i.e. all data from Table 1, dashed curves).

Fiedler F (1971) The variance spectrum of the horizontal wind velocity at $50 \mathrm{~m}$ above the ground. Beit zur Physik der Atmos 44:187-200

Fiedler F, Panofsky HA (1970) Atmospheric scales and spectral gaps. Bull Amer Meteorol Soc $51: 1114-1119$

Frehlich MH, Chelton D (1986) Wavenumber spectra of Pacific winds measured by the seasat scatterometer. J Phys Oceanogr 16:741-757

Fritts D, van Zandt T (1987) Effects of Doppler shifting on the frequency spectra of atmospheric gravity waves. J Geophys Res 92:9723-9732

Gage K, Nastrom G (1985) On the spectrum of atmospheric velocity fluctuations seen by MST/ST radar and their interpretation. Radio Sci 20:1339-1347

Gage K, Nastrom G (1986) Theoretical interpretation of atmospheric wavenumber spectra of wind and temperature observed by commercial aircraft during GASP. J Atmos Sci 43:729-740

Goldman J (1968) The power spectrum in the atmosphere below macroscale. Tech. rep., Institude of Storm Research of St. Thomas, Housen, Texas, TRECOM 365G5-F

Griffith HL, Panofsky HA, van der Hoven I (1956) Power spectrum analysis over large ranges of frequency. J Meteorol 13:279-282 
Heggem T, Lende R, Løvseth J (1998) Analysis of long time series of coastal wind. J Atmos Sci 55:2907-2917

Högström U, Hunt J, Smedman AS (2002) Theory and measurements for turbulence spectra and variances in the atmospheric neutral surface layer. Boundary-Layer Meteorol 103:101124

Kaimal J, Finnigan J (1994) Atmospheric boundary layer flows. Oxford University Press, New York, 289 pp

Kim K, Adrian R (1999) Very large-scale motion in the outer layer. Phys Fluids 11:417-422

Kristensen L (1998) Time series analysis, dealing with imperfect data. Tech. Rep. Risoe-I1228(EN), 31 pp, Ris $\emptyset$ National Laboratory, Roskilde, Denmark

Kristensen L, Kirkegaard P, Fairall C, Kaimal J, Lenschow D (1992) Advantages of tapering of finite data records for spectral analysis,. Tech. rep., National Oceanic and Atmospheric Administration, Environmental Research Laboratories, NOAA Technical Memorandum ERL WPL-226

Larsen SE, Courtney M, Mahrt L (1990) Low frequency behavior of horizontal velocity spectra in stable surface layers. Nineth Symposium on Turbulence and Diffusion, American Metrorol Society pp 401-404

Larsén XG, Kruger A (2014) Application of the spectral correction method to reanalysis data in South Africa. J Wind Eng Ind Aerodyn 133:110-122

Larsén XG, Mann J (2006) The effects of disjunct sampling and averaging time on mean maximum wind. J Wind Eng Ind Aerodyn 94:581-602

Larsén XG, Ott S, Badger J, Hahmann AH, Mann J (2012) Recipes for correcting the impact of effective mesoscale resolution on the estimation of extreme winds. J Appl Meteorol Climat 51(3):521-533, DOI 10.1175/JAMC-D-11-090.1

Larsén XG, Vincent CL, Larsen S (2013) Spectral structure of the mesoscale winds over the water. Q J R Meteorol Soc 139:685-700, DOI DOI:10.1002/qj.2003

LeMone M (1976) Modulation of turbulence energy by longitudinal rolls in an unstable planetary boundary layer. J Atmos Sci 33:1308-1320

Lenschow D, Mann J, Kristensen L (1994) How long is long enough when measuring fluxes and other turbulence statistics? J Atmos Ocean Technol 11:661-673

Lilly D, Petersen E (1983) Aircraft measurements of atmospheric kinetic energy spectra. Tellus 35A:379-382

Lindborg E (1999) Can the atmospheric kinetic energy spectrum be explained by twodimensional turbulence? J Fluid Mech 388:259-288

Lumley JL, Panofsky HA (1964) The structure of atmospheric turbulence. Monographs and Texts in Physics and Astronomy, vol XII. Interscience Publishers. John Wiley \& Sons, New York, 239 pp

Nastrom G, Gage K (1985) A climatology of atmospheric wavenumber spectra of wind and temperature observed by commercial aircraft. J Atmos Sci 42:950-960 
Oort AH, Taylor A (1969) On the kinetic energy spectrum near the ground. Mon Weather Rev 97:623-636

Panofsky HA, Dutton JA (1984) Atmospheric Turbulence. Models and Methods for Engineering Applications. John Wiley \& Sons, Inc., New York, 434 pp

Panofsky HA, McCormick (1954) Properties of spectra of atmospheric turbulence at $100 \mathrm{~m}$. Q J R Meteorol Soc 80:603-606

Panofsky HA, Van der Hoven I (1955) Spectra and cross-spectra of velocity components in the mesometeorological range. Q J R Meteorol Soc pp 603-606

Peña A, Floors R, Wagner R, Courtney M, Gryning SE, Salthe A, Larsén XG, Hahmann AN, Hasager C (2015) Ten years of boundary-layer and wind-power meteorology at Høvsøre, Denmark. Boundary-Layer Meteorol in Revision

Petersen E (1975) On the kinetic energy spectrum of the atmospheric motions in the planetary boundary layer. Tech. Rep. RIS $\varnothing 285$, Ris $\varnothing$ National Laboratory, Roskilde, Denmark, http://www.risoe.dk/rispubl/reports_INIS/RISO285.pdf

Petersen E, Troen I, Frandsen S, Hedegaard K (1981) Wind atlas for Denamrk. A rational method for wind energy siting, 229 pages. Tech. rep., Ris $\emptyset$ National Laboratory

Skamarock W (2004) Evaluating mesoscale NWP models using kinetic energy spectra. Mon Weather Rev 132:3019-3032

Smedman AS (1991) Occurrence of roll circulation in a shallow boundary layer. BoundaryLayer Meteorol 51:343-358

Smedman AS, Bergström H, Högström U (1995) Spectra, variance and length scales in a marine stable boundary layer dominated by a low level jet. Boundary-Layer Meteorol 76:211-232

Smedman-Högström AS, Högström U (1974) Spectral gap in surface-layer measurements. J Atmos Sci 32:660-672

Tchen C, Larsen S, Pécseli H, Mikkelsen T (1985) Large-scale spectral structure with a gap in the stably stratified atmosphere. Phys Scripta 31:616-620

Troen I, Petersen EL (1989) European Wind Atlas. Ris $\emptyset$ National Laboratory, Roskilde, Denmark, ISBN 87-550-1482-8, 656 pp

Van der Hoven (1957) Power spectrum of horizontal wind speed in the frequency range from 0.0007 to 900 cycles per hour. J Meteorol 14:160-164

Vickers D, Mahrt L (2002) The cospectral gap and turbulent flux calculations. J Atmos Ocean Technol 20:660-672

Vincent CL, Larsén XG, Larsen SE, Sørensen P (2013) Cross-spectra over the sea from observations and mesoscale modelling. Boundary-Layer Meteorol 146:297-318

Vinnichenko NK (1970) The kinetic energy spectrum in the free atmosphere - 1 second to 5 years. Tellus 22:158-166

Vinnichenko NK, Dutton J (1969) Empirical studies of atmospheric structure and spectra in the free atmosphere. Radio Sci 4:115-126

Weinstock J (1980) A theory of gaps in the turbulence spectra of stably stratified shear flows. J Atmos Sci 37:1542-1549 
800 Wyngaard J (2004) Toward numerical modeling in the "Terra Incognita". J Atmos Sci 56:22222231

Wyngaard J, Clifford S (1977) Taylor's hypothesis and high frequency turbulence spectra. J Atmos Sci 34:922-927 